\title{
Diversity of Endophytic and Rhizosphere Soil Fungi of Avicennia marina in Maravakadu Mangrove Forest
}

\author{
Vijayalakshmi Selvakumar*, Dr. A. Panneerselvam**,Dr. N. Vijayakumar***, \\ Dr. Mohan A. Savery**** and *****Dr. N. Thajuddin. \\ *Research Scholar **Associate professor and Head, P.G and Research Department of Botany and \\ Microbiology, A.V.V.M. Sri Puhpam College, Poondi, Thanjavur.*** Entomologist **** Principal, \\ Perunthalaivar Kamaraj Krishi Vigyan Kendra, Kurumbapet, Puducherry. **** Professor, Department of \\ Microbiology, Bharathidasan University, Tiruchirapalli.
}

\begin{abstract}
Avicennia marina (Tamil: Alai-atti): Avicennia marina is the dominant mangrove species in Muthupet and accounts for about $95 \%$ of the vegetation cover. Endophytic fungus is an endosymbiont which colonize healthy plant without causing any harm. These are relatively unexplored producers of metabolites useful to pharmaceutical industries (Petrini et al., 1992). Endophytic fungi are ubiquitous and have been found in all species of plant (Arnold et al., 2000). The Maraakadu RF Extn. Bit- I was created as per Govt. Ir.no.56675/ FR-III/ 86-9, dt 20.8.87 with an area of 134.05. ha. The Maravakadu RF is located in pattukottai taluk of Thanjavur district. Endophytic fungus is an endosymbiont which colonize healthy plant without causing any harm. Avicennia marina leaves and rhizosphere soil of the plant was collected during four seasons, premonsoon, monsoon, postmonsoon and summer. Phoma sp, Aspergillus sp and Penicillium sp were most frequently isolated.
\end{abstract}

\section{Introduction}

Endophytic fungus is an endosymbiont that live within a plant for least part of his life without causing apparent harm. Dreyfuss and Chapela (1994) estimated that there may be at least one million species of endophytic fungi alone. Almost all plant species harbour one or more endophytic organisms (Tan and Zou, 2001). To date, only a few plants have been extensively investigated for their endophytic biodiversity. The occurrence of endophytic microorganisms in different plant species is extensively studied. The endophytic fungal diversity of Avicennia marina in Maravakadu mangrove forest is not reported so far. The present study forms the first report on the endophyte diversity of Avicennia marina plant of Maravakadu mangrove forest.

\section{* Sample Collection}

\section{Materials And Methods}

Soil sample was collected from Maravakadu mangrove forest Pattukottai taluk of Thanjavur district during four seasons namely

$\begin{array}{ll}>\text { Post monsoon } & \text { - January to March } \\ >\text { Summer } & \text { - April to June } \\ >\text { Pre monsoon } & \text { - July to September } \\ >\text { Monsoon } & \text { - October to December }\end{array}$

\section{* Isolation Of Fungi From Soil -Serial Dilution Agar Plating Method}

In serial dilution agar plate method, a known amount of material is suspended or agitated in a known volume of sterile water blank to make a microbial suspension. Serial dilutions $10^{-2}, 10^{-3}$ to $10^{-7}$ are made by pipetting measured volumes (usually $1 \mathrm{ml}$ or $10 \mathrm{ml}$ ) into additional dilution blanks. Finally $1 \mathrm{ml}$ aliquot of various dilutions are added to sterile petridishes (triplicate for each dilutions) to which are added $15 \mathrm{ml}$ of the sterile, cool PDA medium, supplemented with Sterptopenicillin, $10 \mu \mathrm{g} / \mathrm{ml}$. The dilutions $10^{-2}$ to $10^{-5}$ are selected for enumeration of fungi. Upon solidification, the plates are incubated in an inverted position for $3-7$ days at $25^{0} \mathrm{C}$.

\section{Fungal Endophytes}

- Sample Collection

Fresh, senescent and matured leaves of Avicennia marina, was collected from Maravakadu mangrove forest Pattukottai taluk of Thanjavur district during four seasons namely premonsoon, monsoon, post monsoon and summer. 


\section{* Isolation Of Endophytic Fungi:}

Three types of leaves were sampled for the investigation of endophytic fungal communities. Healthy and mature plants were carefully choosen for sampling. The surface sterilization usually initializes with plant material being washed in running tap water and soaked in $0.1 \%$ mercuric chloride. The plant material washed is then subjected to dry under airflow (Comcheon et al., 2005). Subsequently a surfactant such as ethanol was employed to rinse the plant material, followed by a sterilizing agent, such as sodium hypochlorite (schulz and Boyle, 2005). Leaves were cut into pieces of about 3-4mm x $0.5-1 \mathrm{~cm}$ length and thereafter, plated onto the culture medium normally potato dextrose agar (PDA) (Suryanarayanan et al., 2003) supplemented with antibiotic agent Streptomycin to restrain bacterial growth until emergence of fungal colony from the plant segments. Afterward, the plates were incubated at temperatures ranging from $18^{\circ} \mathrm{C}$ to $30^{\circ} \mathrm{C}$ for 21 days. Fungal out growth from the plant tissues were sub-cultured on fresh antibiotic- free medium for identification based on morphological examination and conidial characters. Colonization Frequency (CF) was calculated as described by Suryanarayanan et al., (2003).

Colonization frequency of endophytes $=\frac{\text { Number of segments colonized by fungi }}{\text { Total number of segments analyzed }} \mathrm{X} 100$

\section{* Lacto phenol Cotton Blue Mounting:}

A loopful culture was picked up with the help of a sterile inoculation loop and semi permanent slides were prepared using lacto phenol cotton blue. The slides were gently heated in a spirit lamp so as to release the air bubbles, if any present inside the cover glass. The excess stain was removed by using tissue paper and the cover glass was sealed with white nail polish.

\section{* Isolation Of Fungi From Soil}

IV. Results

The soil sample was collected during four seasons namely premonsoon, monsoon, post monsoon and summer. 40 species were recorded in premonsoon, 20 species recorded in monsoon, 35 species recorded in post monsoon and 45 species recorded in summer season. (Table: 1), Aspergillus $s p$, Phoma $s p$ and Penicillium $s p$ were most frequently isolated. (Table: 2), Cladosporium herbarum, Botrytis cinera, Oidiodendron sp. present only in rhizosphere soil. Maximum number of fungi isolated from summer season, minimum number of fungi isolated from monsoon season. Majority of the fungi belongs to Ascomycota and Deuteromycota

Table1: Isolation of Fungi From Soil During Four Seasons

\begin{tabular}{|c|c|c|c|}
\hline \multicolumn{5}{|c|}{ SEASON } \\
\hline PREMONSOON & SUMMER & POSTMONSOON & MONSOON \\
\hline 40 Isolates & 45 Isolates & 35 Isolates & 20 Isolates \\
\hline
\end{tabular}

Table 2: Name of The Fungi Isolated From Soil

\begin{tabular}{|c|l|}
\hline S.NO & \multicolumn{1}{|c|}{ NAME OF THE FUNGI } \\
\hline $\mathbf{1}$ & Aspergillus candidus \\
\hline $\mathbf{2}$ & A. awamori \\
\hline $\mathbf{3}$ & A. flavus \\
\hline $\mathbf{4}$ & A. glaucus \\
\hline $\mathbf{5}$ & A. granulates \\
\hline $\mathbf{6}$ & A. itaconicus \\
\hline $\mathbf{7}$ & A. ochraceus \\
\hline $\mathbf{8}$ & A. niger \\
\hline $\mathbf{9}$ & A. nigricans \\
\hline $\mathbf{1 0}$ & A. nidulans \\
\hline $\mathbf{1 1}$ & A. spinulosus \\
\hline $\mathbf{1 2}$ & A. silvaticus \\
\hline $\mathbf{1 3}$ & A. surphureus \\
\hline $\mathbf{1 4}$ & A. repens \\
\hline $\mathbf{1 5}$ & A. varicolor \\
\hline $\mathbf{1 6}$ & Botrytis cinera \\
\hline $\mathbf{1 7}$ & Candida albicans \\
\hline $\mathbf{1 8}$ & Cladosporium herbarum \\
\hline $\mathbf{1 9}$ & Curvularia subulata \\
\hline $\mathbf{2 0}$ & Fusarium sp \\
\hline $\mathbf{2 1}$ & Fusarium oxysporum \\
\hline $\mathbf{2 2}$ & Trichoderma viride \\
\hline $\mathbf{2 3}$ & Penicillium janthinellum \\
\hline & \\
\hline
\end{tabular}




\begin{tabular}{|l|l|}
\hline $\mathbf{2 4}$ & P. levitum \\
\hline $\mathbf{2 5}$ & P. janthinellum \\
\hline $\mathbf{2 6}$ & Phoma chrysanthemicola \\
\hline $\mathbf{2 7}$ & P. hedoricola \\
\hline $\mathbf{2 8}$ & Phoma $\mathrm{sp}$ \\
\hline $\mathbf{2 9}$ & Oidiodendron $s p$ \\
\hline $\mathbf{3 0}$ & Rhizopus oryzae \\
\hline $\mathbf{3 1}$ & Saccharomyces $s p$ \\
\hline $\mathbf{3 2}$ & Verticillium $s p$ \\
\hline
\end{tabular}

Isolation Of Endophytic Fungi:

Six hundred and ten segments were analyzed. Seventy eight segments colonized by fungi. The overall colonizing frequency was $12.78 \% .12$ fungal species isolated from fresh leaves, 9 fungal species isolated from senescent leaves and 5 fungal species isolated from mature leaves (Table-3). Despite many attempts using different culture media, 2 isolates did not sporulate being classified as Mycelia sterilia and distinguished based on the colour (White or brown) and morphological aspect of the colonies. From those, one from fresh leaves of Avicennia marina and one from decomposed leaves.

TABLE 3: Endophytic Fungi Isolated From Leaves Of Avicennia marina

\begin{tabular}{|c|c|c|c|}
\hline S.NO & FRESH LEAVES & SENESCENT LEAVES & MATURE LEAVES \\
\hline 1. & 12 Isolates & 9 Isolates & 5 Isolates \\
\hline
\end{tabular}

TABLE 4: Name Of The Endophytic Fungi Isolated From Leaves Of Avicennia marina

\begin{tabular}{|l|l|}
\hline S.NO & NAME OF THE FUNGI \\
\hline $\mathbf{1}$ & Aspergillus alliaceus \\
\hline $\mathbf{2}$ & A. flavus \\
\hline $\mathbf{3}$ & A. niger \\
\hline $\mathbf{4}$ & A. ochraceus \\
\hline $\mathbf{5}$ & Penicillium levitum \\
\hline $\mathbf{6}$ & P. janthinellum \\
\hline $\mathbf{7}$ & Phoma chrysanthemicola \\
\hline $\mathbf{8}$ & P. hedoricola \\
\hline $\mathbf{9}$ & Phoma sp \\
\hline $\mathbf{1 0}$ & Vegetative mycelium 1 \\
\hline $\mathbf{1 1}$ & Vegetative mycelium 2 \\
\hline $\mathbf{1 2}$ & Candida albicans \\
\hline
\end{tabular}

In this present study Aspergillus alliaceus, A. niger, A. ochraceus, Penicillium levitum, P. janthinellum, Phoma chrysanthemicoloa, Phoma hedoricola, Phoma and Candida albicans were recorded both soil and endophytic fungi.

\section{i. Aspergillus flavus}

Very rapid rate of growth, maturing in about three days. Surface is greenish-yellow to olive and may have a white border. Septate hyphae with rather long conidiophores ( 400-800 X 8-17 $\mu \mathrm{m})$ which have a rather rough texture or even spiny, especially just below the vesicle. Vesicles are spherical to elongate and about $20-$ $45 \mu \mathrm{m}$ wide. Aspergillus flavus can be variable in seriation with most strains being about $20 \%$ biseriate however some strains can be almost entirely uniseriate. Metulae $(8-10 \times 5-7 \mu \mathrm{m})$ cover three quarters to the entire surface of the vesicle from which the phialides $(7-12 \times 3-4 \mu \mathrm{m})$ form. Conidia are globose to ellipsoidal (3-6 $\mu \mathrm{m})$ with smooth to finely roughened walls.

\section{ii. Aspergillus niger}

Rapidly growing on Saboraud-Dextrose Agar starting with a white to yellowish felt-like mat of mycelia, quickly turning black as conida develop the pigment aspergillin during maturation. Reverse remains white to pale in colour. Aspergillus niger on Sabouraud-Dextrose Agar $72 \mathrm{hrs}$ at $30^{\circ} \mathrm{c}$.Black pigment from conidia maturing from center of colony.

Septate, hyaline (clear) hyphae. Conidiophores (Stipes) are long (400-3000 $\mu \mathrm{m})$ with spherical vesicles at the apex measuring 30-75 $\mu \mathrm{m}$. Aspergillus niger is biserate - metulae just about cover the entire surface from 
which the phialides extend. Conidia are globose, brown to black in colour, measure 3.5-4.5 $\mu \mathrm{m}$ in diameter and have a rough surface.

\section{iii. Aspergillus alliaceus}

Colonies on Czapek's agar with whit floccose mycelium spreading rapidly over the surface of the substratum, and quickly producing abundant sclerotia, at first white, later becoming black without yellow or orange colors, ovate to elliptical up to $500-700 \mu$ in horizontal diameter, up to $1,000 \mu$ or more vertical axis, with a depression or pore at the apex. Ascigerous forms not found. Producing few and scattered stalks with heads up to $200 \mu$ in diameter, yellow or becoming ochre to brown in age; stalks up to $1,500 \mu$ by up to $15 \mu$, with walls colorless, smooth, $1.5 \mu$ in thickness, breaking with rough or ragged edges; vesicles up to $40-50 \mu$ in diameter with wall $1.8-2 \mu$ in thickness and showing prominent pores at bases of phialides; phialides, primary 7-12 X 2$4 \mu$, secondary $7-8 \times 2 \mu$, colorless. Conidia faintly yellowish, elliptical to globose, $2.5 \times 3 \mu$ in diameter.

\section{iv. Phoma hedericola}

Phoma hedericola produced brown coloured colonies with regular margin on PDA medium. Reverse side of the colonies were brown. Mycelia were immersed, branched, septate and dark brown in colour. The fungus produced semi immersed pycnidia in medium which were globose, thinwalled and brown in colour. Sometimes the pycnidia were erumpent and unilocular. Pycnidia were separate or aggregated and occasionally confluent on medium. Conidia 4-6.5X 2.5-3.5 $\mu$ in size.

\section{v. Penicillium janthinellum Biourge}

Colonies on wort gelatin bluish-green, gray-green, or bright green, azonate, with surface growth consisting of networks of hyphae and ropes of hyphae, tardily becoming reddish (rubicante); coremia none. Reverse yellow to ochraceous; odor weak. Conidiophores 30-40 X $2 \mu$ arising from creeping hyphae or ropes of hyphae, with all smooth penicillus a single one-sided verticil of metulae with occasionally one branch from a lower node, hence short $15 \mu$ long or 30-50 $\mu$ when branched; metulate 7-10 X 1.5-2 $\mu$ mostly in threes; philides

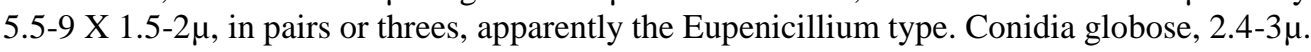

\section{Discussion}

The endophytic fungi are one of the most unexplored and diverse group of organisms that make symbiotic associations with higher life forms and may produce beneficial substance for host (Weber, 1981: Shiomi et al., 2006).

Endophytic organisms have received considerable attention after they were found to protect their host against insect pests, pathogens and even domestic herbivorous (Weber, 1981). Fungi have been widely investigated as a source of bioactive compounds, an excellent example is anticancer drug taxol, which had been previously to occur only in the plants (Strobel and Daisy, 2003).

In the present study 40 species were recorded in premonsoon, 20 species recorded in monsoon, 35 species recorded in post monsoon and 45 species recorded in summer season. Aspergillus sp, Phoma sp and Penicillium sp were most frequently isolated. Cladosporium herbarum, Botrytis cinera, Oidiodendron sp. present only in rhizosphere soil.12 fungal species isolated from fresh leaves, 9 fungal species isolated from senescent leaves and 5 fungal species isolated from mature leaves . Despite many attempts using different culture media, 2 isolates did not sporulate being classified as Mycelia sterilia and distinguished based on the colour (White or brown) and morphological aspect of the colonies. From those, one from fresh leaves of Avicennia marina and one from decomposed leaves.

Endophytes are not host specific (Cohen., 2006) and single endophyte can invade a wide host range. Some strains of the same fungus isolated from different parts of the same plants belongs to the different parts of the same host differ in their ability to utilize different substance (Corell and Petrini, 1983).So, endophytes can be isolated from different families and classes and grow under different ecological and geographical conditions (Petrini et al., 1986).

\section{Conclusion}

Resistance to drugs used in the treatment of bacteria, but also for fungal or parasitic origin is necessary and new resistance problems are emerging, further complicating and rendering many infectious diseases, not only treatment of critical infectious illness more difficult. Increasing prevalence of multi resistant bacteria has turned the search for new antimicrobial agent, an important strategy for alternative therapies useful in the handling of difficult infections. Endophytic fungi have proved to be an important source for bioactive compounds which have wide range of application in medical field. So any information and/or research on 
endophytic fungi such as in this study is value. Hence the present study will help to the detection of potential drugs from endophytic fungi.

\section{Acknowledgment}

The authors are thankful to University Grant Commissions (UGC) for funding through major research project and Perunthalaivar Kamaraj Krishi Vigyan Kendra, Puducherry for their permission to utilize the laboratory facility.

\section{References}

[1]. Arnold A.E., Maynard Z., Gilbert G.S., Coley P.D and Kursar T.A 2000. Are tropical fungal endophytes hyperdiverse? Ecol.Lett.3; 267-274.

[2]. Chomcheon P., Wiyakrutta S., Sriubolmas N., Ngamrojanavanich N., Isarangkul D. and Kittakoop P.2005. 3-Nitropropionic acid (3-NPA), a potent antimycobacterial agent from endophytic fungi : is 3- NPA in some plants produced by endophytes? J. Nat. Prod.68:1103-1105.

[3]. Cohen SD (2006). Microbial Ecology. 52: 463-469.

[4]. Corell GC, Petrini O (1983). Mycologia.75:53-63.

[5]. Dreyfuss M M and Chapela I H (1994), "Potential of fungi in the diversity of novel, low molecular weight pharmaceuticals. In", The discovery of Natural Products with therapeutic Potential (ed Gullo, V.P.)Butterworth- Heinemann, Boston, pp. 49-80.

[6]. Petrini O, Fokkema NJ, Van den Hueval J (1986). Microbiology of the phyllosphere Cambridge. UK Cambridge University Press: $175-187$

[7]. Petrini O, Sieber TN, Toti L, Viret O (1992). Ecology, metabolite production and substrate utilization in Endophytic fungi. Natural toxins.1:188-196.

[8]. Schulz B. and Boyle C. 2005. The endophytic continuum. Mycol. Res. 109(6): 661-686.

[9]. Shiomi, H.F., H.S.A. Silva, I.S. De Melo, F.V. Nunes and W. Bettiol. 2006. Sci. Agric.,63 (1):32-39.

[10]. Strobel G and Daisy B (2003), "Bioprospecting for microbial endophytes and their natural products", Microbiology and Molecular Biology Review, Vol . 67, pp.491-502.

[11]. Suryanarayanan T.S., Venkatesan G. and Murali T.S 2003. Endophytic fungal communities in leaves of tropical forest trees: Diversity and distribution patterns. Curr. Sci. 85: 489-493.

[12]. Tan RX, Zou WX (2001) Endophytes: a rich source of functional metabolites. National Product Reports 18: $448-459$.

[13]. Weber J (1981), “A natural control of Dutch elm disease,” Nature, London, Vol. 292, pp. 449-451. 